\title{
RESENTIMIENTO COMO RESPUESTA EMOCIONAL AL DAÑO EN DOS GRUPOS DE MUJERES EN EL CONFLICTO ARMADO EN COLOMBIA ${ }^{1}$
}

\section{Resentment like an emotional response to damage in two women's groups in the armed conflict in Colombia}

\author{
Orlando Arroyave Álvarez ${ }^{2}$
}

Recibido: 2018-09-18 Aceptado: 2018-11-25

\begin{abstract}
Resumen: Este artículo de investigación tiene como objetivo contrastar el resentimiento como respuesta al daño en dos grupos de mujeres, cuyos hijos o familiares padecieron actos criminales (desaparición forzada, tortura, ejecuciones extrajudiciales) por grupos armados (reinsertados, paramilitares, Ejército). Un primer grupo está conformado por mujeres que habitan en un barrio popular, ubicado en la zona nororiental de Medellín, que participaron de encuentros para pensar el daño y las respuestas morales para enfrentarlo. El segundo grupo está conformado por mujeres entrevistadas en forma individual, que tienen una larga experiencia de denuncias por crímenes contra sus hijos y familiares a la luz del discurso de los derechos humanos. El resentimiento es una emoción presente en los dos grupos de mujeres, teniendo consecuencias en sus lazos cercanos, en su concepción sobre la sociedad e incluso sobre su propia identidad personal y colectiva. El resentimiento no solo produce un efecto de impotencia, sino que puede servir como un movilizador para la acción política.
\end{abstract}

Palabras Clave: Daño, resentimiento, emociones negativas, conflicto armado

\begin{abstract}
This article aims to contrast the resentment in response to damage in two groups of women, whose children or relatives suffered criminal acts (forced disappearance, torture, extrajudicial executions) by armed groups (reinserted, paramilitary, Army). The first group is conformed of women who live in a popular neighborhood, located in the northeastern area of Medellín, who participated in meetings to think about the damage and moral responses to face it. The second group is conformed of women interviewed individually, who have a long experience of reporting crimes against their children and relatives in light of the discourse on human rights. Resentment is an emotion present in the two groups of women, having consequences in their close ties, in their conception of society and even their own personal and collective identity. Resentment not only produces an impotence effect, but it can serve as an engine for political action.
\end{abstract}

Keywords: Damage, resentment, negative emotions, armed conflict
Para citar este artículo en APA: Arroyave, O. (2019). Resentimiento como respuesta emocional al daño en dos grupos de mujeres en el conflicto armado en Colombia. Revista de Psicologia Universidad de Antioquia, 11(1), 93-115. DOI: https://doi. org/10.17533/udea.rp.v11n1a04
Artículo derivado de la investigación "Mal moral y perdón como posible respuesta ética ante el dańo", financiada por el Comité para el desarrollo de la Investigación (CODI) de la Universidad de Antioquia. El autor participó como estudiante de doctorado de Ciencias Sociales.

Psicólogo, Magíster en Filosofía y Doctor en Ciencias Sociales. Profesor Departamento de Psicología, Universidad de Antioquia. Correo: edgar.arroyave@udea.edu.co; https://orcid. org/0000-0002-4117-3552 


\section{Introducción}

El resentimiento es una emoción que ha cobrado importancia en las dos últimas décadas en los estudios de las ciencias sociales que buscan comprender fenómenos como las protestas sociales actuales (Jasper, 2013), los populismos de derechas o izquierda (Maldonado, 2017), o los sentimientos morales y políticos de las víctimas, que más allá del perdón, mantienen el fuego de la rabia, el odio o la venganza.

Este sentimiento, tradicionalmente ha abordado por la filosofía en términos negativos, principalmente por filósofos románticos como Max Scheler (Reyes, 1944) y Nietzsche (Escríbar, 2000), fue abordado por el discurso científico en el trabajo pionero de Darwin, en 1873 intitulado La expresión de las emociones en los animales y en el hombre (Darwin, 1998). Este científico, que se ocupó en este trabajo de las 'emociones negativas', las cuales analizaba a través de expresiones faciales (cejas fruncidas y labios hacia adelante), buscaba la universalidad de estas, más allá de una cultura particular. El 'ánimo resentido' abarcaba, según Darwin, un amplio espectro de respuestas emocionales que iban desde la irritación o la rabieta del niño hasta la furia o el descontento del adulto con otro humano por una ofensa recibida; comportamiento que podía ser observado tanto en los ingleses de su tiempo como en comunidades indígenas de Suramérica o África. A pesar de que no definía el resentimiento, Darwin lo caracterizaba como una expresión de malestar emocional por el daño o la 'ofensiva' recibida por parte de otras personas.

Continuando con la tradición de la búsqueda de la universalidad de esta emoción, a través de estudios empíricos, en la actualidad la psicología tanto evolutiva como social, a través de técnicas experimentales, han puesto de manifiesto diversas expresiones de ésta, como la envidia, la rivalidad o la Schadenfreude (o el disfrute por el mal ajeno) (Smith, 2016).

En muchos trabajos contemporáneos, más allá de esta propuesta evolutiva, se ha subrayado la importancia de pensar las emociones negativas para entender fenómenos sociales propios de la época presente como las revueltas, el populismo o el racismo. Ya sea desde una perspectiva histórica y política, como desencanto por el proyecto de modernidad desde sus orígenes hasta el 
presente (Mishra, 2017; Nussbaum, 2019); como una política cultural de Estado o de grupos que buscan expulsar o eliminar a través del odio a los grupos considerados peligrosos o despreciados socialmente (Ahmed, 2015; Fukuyama, 2019); como una manifestación emocional negativa que mina o destruye la 'compasión cívica', fundamental en una democracia liberal (Nussbaum, 2014); en cada una de estas manifestaciones emocionales consideradas como negativas (el miedo, la vergüenza, la envidia, el odio y la agresividad), se dan múltiples fenómenos que merecen el interés de la academia y de la sociedad en general como el populismo (Judis, 2018), el malestar cultural que genera el encuentro amoroso (Illouz, 2012) o el sentimiento de soledad que sufren millones de personas en las grandes ciudades (Laing, 2017). El resentimiento, que se manifiesta principalmente en la rabia, parece ser la expresión fundamental en la época contemporánea (Mishra, 2017; Nussbaum, 2019; Traister, 2019), junto con otra emoción, señalada por algunos autores, como es la vergüenza (Demertzis, 2013). De acuerdo con los trabajos anteriores, son pocas las investigaciones o reflexiones teóricas que han subrayado la importancia de la compleja manifestación del resentimiento en sus dimensiones políticas y morales, como un motor para la rebelión, la emancipación o la reivindicación social de derechos (Traister, 2019), así contenga "un ardiente deseo de desquite" (Nussbaum, 2019).

Esta emoción es un fenómeno subjetivo pocas veces trabajado en el conflicto armado colombiano, a pesar de su largo periodo de violencia y su extenso número de afectados que, solo en las tres últimas décadas, ha dejado ocho millones de víctimas. Algunos trabajos de investigación en Colombia han asociado a ciertas figuras políticas como el conservador Laureano Gómez (Socarras, 1994) o el perpetrador de asesinatos masivos Carlos Castaño (Salas, 2008) con el resentimiento, o a las víctimas con sueños de 'venganza' (Lefranc, 2017). A pesar de la importancia de esta emoción moral y política, ha sido poco abordada en las investigaciones sobre el conflicto armado, en las que suelen aparecer nociones como 'rabia', 'odios', 'venganza', etc.

El presente artículo, teniendo en cuenta la experiencia concreta de mujeres afectadas por el conflicto armado colombiano, contrasta las consecuencias del resentimiento como respuesta al daño en dos grupos de mujeres, cuyos hijos o familiares padecieron actos criminales. Un primer grupo, está conformado 
por mujeres que habitan en un barrio popular, ubicado en la zona nororiental de Medellín que participaron en un grupo reflexivo para pensar el daño y las respuestas morales para enfrentarlo, como la indignación. El segundo grupo, estaba conformado por tres mujeres entrevistadas en forma individual, que tienen una larga experiencia de denuncia por crímenes contra sus hijos y familiares a la luz del discurso de los derechos humanos.

El trabajo consta de cuatro puntos centrales. Primero, un examen del concepto de resentimiento; segundo, una exposición de la multiplicidad de herramientas metodológicas para la obtención de la información; tercero, una exposición de los resultados de estos encuentros haciendo un contraste entre los dos grupos de mujeres, empoderadas y no empoderadas; y cuarto, una reflexión que sintetiza la importancia de pensar el resentimiento en fenómenos como la violencia y el conflicto armado.

\section{Definición de un sentimiento impreciso}

Como afirma la neurocientífica Lisa Feldman es difícil dar una definición precisa de las emociones, pues cada forma expresiva de las mismas hace parte de una realidad social tan compleja que la ciencia no puede proponer una delimitación conceptual o una metodología exacta para abordarlas sin considerar los contextos sociales, e históricos (Feldman, 2018). Las realidades sociales y las subjetividades dependen de contextos cambiantes, y las emociones son, en palabras de Feldman (2018), "conceptos" amplios que admiten variabilidad, ambigüedad y respuestas múltiples. Como cualquier animal, los humanos estamos, en palabras de Harari (2016), controlados por algoritmos biológicos "que operan mediante sensaciones, emociones y pensamientos" (p. 101); más las emociones, expresión de esos algoritmos biológicos, se manifiestan en una pluralidad de sensaciones y en diversos campos adaptativos, que quizá no requieran de unas "huellas dactilares" precisas (Feldman, 2018), ubicadas en zonas específicas del cerebro, o como expresión facial universal única o una respuesta corporal codificada.

Pero más allá de este debate, entre el modelo universalista darwiniano de las emociones y la teoría de la construcción subjetiva, social y cultural de las 
emociones (Feldman, 2018), que retoma la vieja disputa sobre el peso de la biología o la cultura en la denominada naturaleza humana, como si una dominase a la otra, la experiencia de los sujetos concretos muestra que las emociones son una red de combinaciones de expresiones sensoriales, conceptos y reacciones íntimas y a la vez públicas que requieren ser abordadas en forma puntual. Esto se pone en evidencia, cuando tomamos un concepto emocional polisémico, difícil de delimitar, con múltiples expresiones, como es el resentimiento, en un contexto de guerra. Esta emoción (o múltiples emociones) que agrupamos bajo el concepto de resentimiento tiene consecuencias políticas y éticas para los sujetos, la sociedad e incluso las formas de gobierno actual. Por lo tanto, esta emoción, engloba una madeja de sensaciones o expresiones morales y psicológicas a veces difícil de definir, clasificar o articular en forma causal o secuencial. Sin embargo, es un fenómeno que acompaña la guerra, junto con la memoria y las experiencias de los sobrevivientes de este acontecimiento colectivo.

Por el momento, podemos considerar el resentimiento como un estado emocional de malestar por el daño que otro individuo o un grupo le infligió a alguien, cuya característica principal es el rencor por la ofensa recibida por otra persona, que se considera como hostil, enemiga o victimario. Se suele caracterizar a esta emoción como la reacción afectiva "que experimentamos cuando alguien nos causa una ofensa o una injusticia” (Díaz, 1994, p. 11); es la manifestación emocional de un agravio que el sujeto — que lo manifiestaconsidera como un atentado o un dańo para su integridad humana. Cuando nombramos resentimientos indicamos reacciones sentimentales negativas contra un individuo, un colectivo, estilos de vida o formas de gobierno o de poder por una ofensa real o imaginaria que corroe la dignidad del ofendido o los afectados.

Para una tradición filosófica o religiosa, este sentimiento es concebido como el envés del perdón. Para el filósofo del siglo XVIII, el obispo Butler, por ejemplo, este se dirige a un otro que me ha infligido un daño; lo que se anhela es herir, destruir o producir algún mal al ofensor. Es tan radical este sentimiento que, para Butler, "Ningún otro principio ni pasión tiene como el fin el sufrimiento de nuestros congéneres", como sucede con el resentimiento (citado por Nussbaum, 2019, p. 91). El resentimiento es la contracara del 
perdón, pues, según el obispo Butler, "el perdón es el proceso que realiza la víctima de retractarse y renegar (forswearing) del resentimiento que sentía por el victimario" (como se cita en Rueda, 2012, p. 98).

Por ser considerado 'negativo', se le asocia como un sentimiento que sus portadores no deberían sentir o al menos ser modificados por otro más positivo. El resentimiento así pensado, es un acto antisocial, pues niega cualquier posibilidad de restablecer la ligazón entre la víctima y el victimario. Esta forma de concebirlo, quizá pueda ser cuestionada, ya que se espera de quien reacciona de este modo una respuesta como el perdón.

Este sentimiento negativo reactivo ante el socavamiento de la dignidad por parte de un otro, según algunos autores, produce "una autointoxicación psíquica que surge al reprimir sistemáticamente los afectos y las descargas emocionales normales" (Buela, 2009, p. 144). El fenómeno más presente, de acuerdo con esta concepción de este sentimiento así concebido, es la impotencia, pues se suele asociar con la represión del impulso de venganza o la imposibilidad práctica de ejecutar una respuesta hacía el responsable. Esto no significa, sin embargo, que expresar estos sentimientos de venganza, logren plenamente en muchos casos sofocar o aliviar este sentimiento de autointoxicación. Por ahora, digamos, siguiendo a Buela (2009), que lo que define al resentimiento no es la impotencia o el impulso de venganza, sino el "rencor" o el "odio retenido" (p. 145), por el daño padecido, supuesto o real. El "amargor" es el tono emocional que guía el resentimiento, en sus múltiples manifestaciones. Las reacciones sentimentales asociadas con éste, son plurales; la envidia, el odio, el sentimiento de venganza, la rabia con otro, etc. Pero a diferencia de reacciones inmediatas, el resentimiento se asocia con un sentimiento que se prolonga en el tiempo. El resentimiento reconfigura la experiencia de sí que tiene quien la padece. Desde una perspectiva no explorada por Axel Honneth, este rencor por el daño padecido, es una reacción por el no reconocimiento. Para Honneth (2010), el desprecio al otro implica una desvalorización de la persona que recibe la ofensa o no reconocimiento, lo que tiene consecuencias en la forma en que el sujeto se autopercibe. De acuerdo con Honneth, daños como el abuso físico, la negación de los derechos y la degradación de un sujeto tienen consecuencias en la forma en que su autovaloración, afectando sus 
posibilidades de su autorrealización, perdiendo su autoconfianza y su autorrespeto, poniendo en riesgo su autoestima.

\section{El resentimiento en su manifestación privado y pública}

Jean Améry (2001) propuso, desde su experiencia como prisionero de un campo de concentración, durante el periodo nazi, rescatar el resentimiento como sentimiento considerado negativo, para darle un lugar dentro de las expresiones propias de la indignación vital de las víctimas. Para Améry, esta expresión emocional les permite a éstas conservar una indignación moral por el daño padecido; así concebido, puede conservar un potencial moral para mostrar que el daño permanente padecido no se puede eliminar solo con la invocación social del perdón. La conciencia política del resentimiento surge entonces de la víctima como una reacción frente al verdugo, cuya acción nunca podrá ser borrada. Mientras este sentimiento "negativo", era concebido por Nietzsche (Marrades, 2004), como un falseamiento de la realidad, para esta concepción, por el contrario, éste es la manifestación de la imposibilidad de edulcorar la realidad y la posibilidad de denunciar abiertamente al perpetrador por su acto, más allá de la impunidad o las amnistías o los actos colectivos de perdón, promovidos por los Estados para normalizar las relaciones entre los asociados después de un conflicto social o una guerra. Jean Améry propone una transformación de los valores, en contraposición a la lectura de Nietzsche sobre los sentimientos negativos. Mientras Nietzsche afirma que los juicios morales encubren el resentimiento, para Améry no hay nada que encubrir (Marrades, 2004). Su resentimiento es abierto y justificativo. No se busca reprimir y sublimar el rencor; no busca la falsa paz interior y social que se cimienta sobre la negación de las atrocidades padecidas, en su caso, por la comunidad judía a la que él pertenecía.

Así concebido este sentimiento, implica una autoafirmación en que el sujeto se erige en un obstáculo ético-político contra la pretensión de olvido y perdón; un instrumento de verdad que denuncia la verdad impuesta por los verdugos. Améry escribe: "Mi resentimiento existe para exigir que los verdugos paguen con la misma moneda [lo] que me hicieron pagar a mí" (citado por Marrades, 2004, p. 226). 
Se dirá que es una pobre respuesta ante la magnitud de lo sufrido; pero el trabajo de Jean Améry es la constancia de que lo más importante para los que han soportado vejaciones, es hacer inextinguible lo padecido, identificando los hechos, señalando al verdugo y mostrando que la destrucción de la dignidad humana no afecta a un individuo, sino a la comunidad de la humanidad que incluye a todos los hombres y las mujeres.

En su propuesta, este autor, busca, más allá de la venganza o la expiación, que los perpetradores, promotores y auxiliares reconozcan lo que se niegan a reconocer, que son responsables de los crímenes que han sido trivializados por la 'memoria histórica' del dolor colectivo e individual. Así como la víctima se sabe víctima, el verdugo sabe que es verdugo, aunque lo niegue; es un criminal que ha socavado la idea moderna de dignidad humana. El verdugo ha falseado o distorsionado la realidad para imponer su voluntad sobre el otro.

\section{¿Cómo abordar el resentimiento?}

Durante la investigación Mal moral y perdón como posible respuesta ética ante el daño, realizada en la ciudad de Medellín y en otras dos ciudades colombianas (Soacha, San Carlos), entre 2013-2016, cuyo objetivo consistía en explorar sobre el perdón y las prácticas asociadas a éste, nos encontramos lo que hemos denominado el resentimiento y sus múltiples manifestaciones en mujeres cuyos hijos, esposos o familiares fueron asesinados, desaparecidos, torturados o abusados sexualmente.

En su inicio, la investigación tuvo como referente talleres exploratorios para abordar el perdón en un grupo de mujeres que respondieron a la convocatoria del equipo de investigación. Las mujeres ya participaban en distintas actividades propuestas por la Fundación Solidaridad y Compromiso, una organización no gubernamental (ONG) que tiene como misión:

Fomentar el desarrollo social de las mujeres cabeza de familia, jóvenes y niños, mediante la creación de centros en donde se conformen grupos [...] víctima de la violencia para lograr la reconciliación, la formación para la convivencia y la autonomía económica. (Fundación Solidaridad y Compromiso) 
En un principio, como actividad motivadora, se propuso una cartilla de la Institución, pero poco a poco el grupo de mujeres que se reunían quincenalmente fueron expresando sus sentimientos sobre el daño padecido por ellas, sobre la memoria traumática que marcó sus vidas a partir de este evento, los procesos de duelo, las manifestaciones físicas y psicológicas de este dolor, su desprecio o desconfianza por las instituciones como la policía o las encargadas de administrar justicia, entre otros temas. Durante cerca de dos años, estas siete mujeres pudieron expresar sus experiencias dolorosas, transformando ese dolor privado o familiar en un acontecimiento compartido, no solo con sus vecinas o compañeras de grupo, sino con el equipo interdisciplinario conformado por dos filósofos, un psicólogo y varios estudiantes de múltiples disciplinas (antropología, derecho, filosofía, entre otras).

Los talleres, entonces, que en un principio se propusieron como parte del programa de esta ONG, denominado "Escuelas de perdón y reconciliación", para el control de rabias, rencores y deseos de venganza, se transformaron en una experiencia vital para ellas, que al final, entre el grupo de investigadores y las mujeres participantes se elaboró una cartilla diferente a la propuesta por la institución, y que reflejaba los significados y experiencias de estas mujeres que resumieron en tres capítulos: "Dańo, dolor y emociones", "Memoria y testimonio" y "Confianza, estima y perdón”.

Como una actividad complementaria, no prevista en el diseño inicial del proyecto de investigación, se realizaron entrevistas a tres mujeres defensoras de derechos humanos en torno a conceptos como daño, dolor, memoria, testimonio y perdón. A diferencia de las siete mujeres anteriores, que solicitaban que no se divulgara sus nombres, en los consentimientos informados, las tres defensoras reivindican sus nombres como parte de su actividad política en defensa de las víctimas del conflicto armado: Fabiola Lalinde, a quien su hijo fue torturado, asesinado y luego desaparecido por el Ejército colombiano; Pastora Mira, quien padeció desplazamiento y el asesinato de su esposo y la desaparición de su tercera hija, por grupos paramilitares de derechas y guerrilleros de izquierda; y Luz Marina Bernal, cuyo hijo, con déficit cognitivo, fue asesinado por el Ejército colombiano, y luego presentado con vestido camuflado para hacerlo pasar como guerrillero (ejecuciones extrajudiciales, denominadas popularmen- 
te como "falsos positivos"). Cada una de estas mujeres ha luchado por obtener justicia para los suyos, pero han ampliado sus luchas, creando y apoyando organizaciones encargadas en la defensa de los derechos humanos en Colombia.

\section{Tipo de investigación}

Esta investigación es cualitativa y exploratoria y, por lo tanto, le interesa las percepciones, opiniones y sentimientos expresados por estas mujeres, teniendo como eje el daño y el perdón, para capturar algunas características otorgadas por éstas al daño padecido y sus respuestas morales y éticas. Es exploratoria, pues en la búsqueda de investigaciones sobre el perdón y los sentimientos morales que lo acompañan, no se encontraron trabajos empíricos que se ocuparán del tema. Igualmente, no hay trabajos empíricos sobre el resentimiento en Colombia.

Lo importante de esta investigación, además de los temas de los que se ocupa, es la convergencia de múltiples disciplinas (filosofía, antropología, psicología y derecho) que desde sus múltiples saberes y técnicas buscan que estas mujeres expresen su concepción sobre temas siempre en construcción y en discusión, como el perdón y el daño, que puede orientar futuras investigaciones sobre los sentimientos morales asociados a fenómenos de violencia masiva.

\section{Técnicas}

Las técnicas utilizadas se pueden dividir en dos: 1) grupos tanto focales como de reflexión; y 2) entrevistas focales. A continuación, se expondrán brevemente el uso de estas técnicas en esta investigación.

Durante dos años, se hicieron dos encuentros mensuales con un grupo de mujeres, quienes participaron de las actividades propuestas. Estas mujeres eran, en su mayoría desplazadas del campo a la ciudad, sin una escolaridad más allá de la primaria, con bajos ingresos económicos, trabajando en casas de familia, o sostenidas económicamente por sus esposos o hijos; solo una de estas mujeres que participaron en los talleres, contaba con una pequeña tienda de abarrotes de su propiedad, en el barrio donde vivían todas las mujeres. 
Si bien en un principio se utilizó como pretexto una cartilla en torno al perdón, como ya se indicó, lo que se buscó fue, ante todo, que las mujeres pudieran expresar sus opiniones y sentimientos en forma libre. En cada encuentro se utilizaron múltiples materiales y técnicas, como pequeñas lecturas sobre el tema abordado (perdón, memoria personal y colectiva, etc.), videos motivacionales, breves exposición sobre los temas y actividades de tejidos. Estos encuentros fueron grabados en audio, con el consentimiento de las participantes, siempre y cuando, hubo consenso en el grupo, no se diera a conocer el nombre de estas.

Cada encuentro tenía como objetivo que las mujeres reflexionaran en torno a los temas propuestos, desde sus perspectivas personales. En reflexiones puntuales, por ejemplo, sobre el duelo de la muerte de sus hijos, las mujeres contaban sus experiencias personales sobre el asesinato de sus hijos, aunque también traían elementos teóricos como los distintos momentos del proceso de elaboración por la pérdida (negación, ira, negociación, depresión y aceptación), aprendidos durante una 'capacitación' que les había ofrecido una psicóloga que realizó algunos encuentros sobre el tema del duelo, en otro trabajo colectivo ofrecido por la Fundación Solidaridad y Compromiso.

Lo que se privilegiaba en este trabajo era, sin embargo, las experiencias personales de cada una de estas mujeres, cómo habían tramitado con el dolor de sus vidas, las pérdidas, el dolor, el resentimiento por lo padecido, y otros temas conexos propios de las preguntas en torno al daño y el perdón. Algunas mujeres, igualmente, participaron de entrevistas a profundidad en forma individual.

En cuanto a las entrevistas focales, que no estaban planeadas al inicio de este proyecto de investigación, se contactó a tres defensoras de derechos humanos, cuyos familiares (hijos, esposos) fueron desaparecidos y asesinados por diferentes grupos armados irregulares (guerrilleros de izquierda, paramilitares) y regular (Ejército Nacional).

Cada entrevista tuvo en promedio dos horas, la cual tenía como objetivo explorar el tema del daño que habían padecido y en torno al tema del perdón. Igualmente, cada una de estas entrevistas fueron grabadas con autorización de las participantes. Ellas no pidieron el anonimato, pues consideraban que 
contar sus historias con nombres propios hacía parte de su reivindicación por sus familiares asesinados y desaparecidos, lo cual podía contribuir en su lucha política por los derechos humanos.

\section{Resultados}

Para el presente artículo se han tomado cinco categorías de análisis, las cuales surgieron luego de examinar el material producido por los grupos focales y de reflexión, y las entrevistas focales. Se privilegiaron categorías comunes en los dos grupos de mujeres, teniendo como referente la noción emocional del resentimiento. Las categorías propuestas son: la memoria como experiencia privada y pública; la expresión emocional después del daño; los discursos para tramitar el dolor; el resentimiento y sus afectaciones a otras esferas sociales; y el daño como aliciente para la lucha.

\section{La memoria como experiencia privada y pública}

Tanto en el grupo de mujeres del taller que no estaban empoderadas para reivindicar la justicia por los crímenes contra sus hijos, como en las mujeres defensoras de derechos humanos, se privilegia el recuerdo y el relato de los crímenes de sus familiares. Ninguna de ellas fue testigo de los crímenes, pero su labor de pesquisa por lo acontecido sobre sus seres queridos, ha tejido un relato de ese evento traumático, que incluye fragmentos contados por conocidos o, como en caso de las defensoras de derechos humanos, a partir de investigaciones judiciales y periodísticas.

Exceptuando el caso de Luz Marina Bernal, en todos los relatos aparece la invocación religiosa para condenar, agradecer o justificar a Dios por lo sucedido. Sin embargo, en los relatos de las mujeres defensoras de derechos humanos, se privilegia la lucha por la memoria de su hijo en forma pública y política, sin olvidar los referentes religiosos.

En las mujeres de los talleres, no había una reivindicación de derechos humanos, incluso de justicia; consideraban que sus historias eran tan personales, que se circunscribían al ámbito privado, conformado por sus hijos, esposos, nietos, y algún otro familiar (hermana, abuela, madre) o vecino cercano. 
En todas las mujeres, independiente de su formación en derechos humanos o no, aparece la indignación por el crimen contra sus familiares. A esa indignación la acompañan odios, rencores rabias, fantasías sádicas contra el victimario. Ese malestar que produjo el daño modificó sus vidas y las de sus familiares sobrevivientes. En el caso de las mujeres defensoras de derechos humanos, su rabia, su impotencia inicial, el dolor por la pérdida, las llevó a una lucha por el reconocimiento, no solo jurídica sino social, con efectos políticos y éticos públicos; sus casos privados, adquirieron la fuerza de lo colectivo.

\section{La expresión emocional después del daño}

Como ya se advirtió, durante los encuentros con las mujeres del taller y con las defensoras de derechos humanos, no se buscaba explorar el fenómeno emocional, que denominamos con imprecisión, como resentimiento, pero este emergió una y otra vez. A lo largo de los encuentros grupales y las tres entrevistas, aparecen sentimientos 'negativos', por el daño recibido, como 'el odio', 'rabia', 'ganas de no vivir', 'tristeza', 'desconfianza', 'rencor', 'frustración', 'autocompasión', 'impotencia', 'fantasías sádicas', etc.

A los efectos de este dolor padecido, que se manifiesta en somatización de la pérdida, como dolor de cabeza, somnolencia, desánimo para realizar actividades, entre otras manifestaciones, ellas los asocian con su depresión, su rabia, su impotencia, su angustia por estas pérdidas irreparables.

En todos los casos, hubo un periodo de depresión por la pérdida que generaba impotencia y dificultades de retornar a su vida social y familiar habitual. En los casos de las tres mujeres que sus familiares estaban desaparecidos, la depresión inicial se acompañaba por un sentimiento de zozobra por el destino de éstos. En cada caso, las mujeres recreaban mentalmente el final de sus seres queridos, sus últimos momentos de agonía o padeciendo torturas por parte de sus victimarios. Cada una de estas mujeres, exceptuando la mujer que su hija fue abusada sexualmente, relata con detalles pormenorizados los asesinatos de sus hijos o esposos. Como decía una de ellas, nos sentimos "psicológicamente o emocionalmente, moralmente y humanamente" devastadas (Molina et al., 2016). 
El daño es sentido como una herida dolorosa en su existencia, con efectos incluso en su identidad: este dolor ha modificado la percepción de sí mismas y del entorno social. El daño es asociado con una herida que no cierra, de algo irreparable en la existencia que ya modificó la vida dejando una sensación de dolor que, aunque pase el tiempo, se siente "como el primer día". En palabras que expresó en forma colectiva una mujer del taller:

El daño o el dolor es una herida que se vive en el alma y que resulta irreparable. Una herida que queda guardada en el cuerpo y permanece allí, viviéndose como algo que no puede comunicarse completamente, que se considera indecible y que puede ser permanente. [Mujer del taller]

Las mujeres del taller coincidían que este daño les había dejado la sensación de poca valía, un menosprecio social, pues sentían que su dolor no importaba a la sociedad. Esta pérdida violenta de sus seres queridos, le hacían perder confianzas en sí mismas y en la sociedad.

Una de ellas afirmó, incluso que, al padecer este dolor, "[una se] vuelve menos humano", pues se torna menos compasiva con los otros. Esa supuesta inhumanidad no es extensiva a su familia, solo a algunos vecinos o la sociedad toda.

\section{Los discursos para tramitar el dolor}

Todas las mujeres, tanto del grupo del taller como las defensoras de derechos humanos, con la excepción de una mujer que no expresó o no utilizó el discurso religioso en su narrativa, todas tienen como referencia imágenes y frases religiosas. En uno de los casos, una mujer tuvo un periodo anti-religioso que incluyó el acto iconoclasta de la destrucción de una figura de una virgen que, sus según palabras, "no había cuidado a mi hijo", a pesar de que ella se lo había encomendado a su protección. Ella afirmó que había enloquecido por ese dolor, pues había perdido la consciencia religiosa, ofuscada por la rabia o el dolor por la pérdida del hijo asesinado. Esas creencias religiosas no impidieron, sin embargo, que alguna de ellas recree en uno de los encuentros una fantasía sádica de tortura y asesinato contra el victimario de su hijo. 
En las restantes mujeres, el discurso religioso sirve de clave para explicar esta experiencia, como designio, como consuelo (Dios y la virgen me ayuda, Dios no desampara) o castigo o perdón (Dios es el único que perdona: "quien hace el mal, lo paga”); sin embargo, en caso de las defensoras de derechos humanos, predomina la invocación a justicia, la memoria y la dignidad humana, que también se suele asociar con Dios.

En el caso de las mujeres empoderadas, que buscan justicia y memoria por los crímenes padecidos por sus seres queridos, como ya se ha indicado, tienen como referente el discurso de los derechos humanos. Para estas mujeres este discurso tiene como prácticas la denuncia, la búsqueda de justicia, el fortalecimiento de lazos con otros grupos defensores de derechos humanos y el empoderamiento de otras víctimas para que busquen justicia y memoria por sus seres queridos.

\section{El resentimiento y sus afectaciones a otras esferas sociales}

El asesinato de sus hijos genera, relata una de las mujeres del taller, un aislamiento, incluso con sus otros hijos o familiares. Varias manifestaron, después de este evento, una actitud apática con vecinos y familiares lejanos. Si bien poco a poco retornaron a vínculos dejados a un lado por el dolor que les causaba, persistió un sentimiento de desconfianza a personas extrañas. Una defensora de derechos humanos, Fabiola Lalinde, afirmó que durante los primeros días de la desaparición de su hijo Fernando, ella tuvo una fase de depresión, pero que, desde los primeros días, cuando comprendió que éste había sido objeto de "desaparición forzada", decidió emprender la búsqueda de éste en cuarteles o denunciar ante la justicia (que ella señala como cómplice de este crimen) este crimen de lesa humanidad. Desde ese momento se convirtió en una activista en defensa de los derechos humanos, sacrificando incluso a su familia por esta causa de justicia.

Mientras las mujeres del taller, contaban con apoyo de los familiares cercanos (esposos, hijos, padres, tíos, primos), a pesar de su aislamiento social, en el caso de las defensoras de los derechos humanos, por el contrario, sus esposos o compańeros sentimentales e incluso sus hijos, rompieron con éstas por su 
activismo; sin embargo, ellas, igualmente relatan cómo este crimen contra sus familiares les permitió establecer nuevos lazos sociales con asociaciones y personas particulares que luchan contra crímenes como la desaparición forzada y las ejecuciones extrajudiciales ("falsos positivos").

En todos los casos relatados, tanto de las mujeres no empoderadas como las defensoras de derechos humanos, la impunidad ha sido total o no se ha logrado un esclarecimiento pleno de lo acontecido. El caso judicial que más lejos ha llegado es de Fabiola Lalinde, defensora de derechos humanos, quien logró que el Estado colombiano fuera condenado por la Comisión Interamericana de Derechos Humanos, el 16 de septiembre de 1988 por desaparición forzada de su hijo, Luis Fernando Lalinde. El Ejército Nacional, igualmente ha pedido perdón, y el Estado debió realizar un documental sobre el caso. A pesar de estos logros en su caso, los militares que participaron en esa brigada nunca fueron sancionados así se conocieran sus nombres y rangos; incluso fueron ascendidos.

Estos actos de impunidad generalizados, hace que todas las mujeres participantes, afirmen que no confían en los mecanismos de la justicia; mientras las tres mujeres defensoras de derechos humanos han denunciado ante organismos judiciales los crímenes de sus familiares, solo una de las mujeres del taller, contó que el asesinato de su hijo fue denunciado ante la Fiscalía de la Nación, encargada de la investigación criminal en nuestro país, pero considera que no hubo acción efectiva para encontrar a los responsables del acto criminal, así como sanción jurídica e incluso social.

Todas las participantes manifestaron malestar, rechazo, desconfianza o desprecio por la justicia colombiana, aunque en el caso de las mujeres defensoras de derechos humanos continuaron reclamando a los distintos organismos judiciales nacionales o internacionales en búsqueda de justicia; igualmente, sus casos han ayudado a que otras mujeres conformen o hagan parte de organizaciones defensoras de derechos humanos que han tomado como bandera, más allá de la justicia, la búsqueda de la memoria de lo acontecido a sus familiares para que cada caso se convierta en emblemático. Las defensoras de derechos humanos así expresaran malestar o rencor por los grupos armados y sus miembros que "desaparecieron", torturaron o mataron alguno de sus familiares, han 
emprendido una lucha por el reconocimiento en la esfera pública, social y jurídica, más allá de la esfera familiar o filial que los acompañaron en su largo proceso de duelo que no ha cesado.

\section{El daño como aliciente para la lucha}

Si bien la expresión emocional del daño es similar en estas mujeres, pues cada una de ellas manifestó rabia, impotencia, depresión, angustia y ganas de no vivir, sus respuestas sociales difieren. En el grupo de las mujeres que participaron en el taller, la mayoría se apoyó en los lazos familiares para recuperar en algo sus vidas. Sus esposos o hijos trataban de ayudarlas en reponerse de un largo periodo de depresión por la pérdida de sus hijos; sin embargo, en todos los casos, ellas consideraban que sus vidas continuaban con ese dolor que no era comprendido plenamente por su familia.

Las tres defensoras de derechos humanos han recurrido a distintas instancias de justicia (Fiscalía, Consejo de Estado, Corte Interamericana de Derechos Humanos) para denunciar los crímenes de sus hijos; y aunque hay sentencias, las tres consideran que hay impunidad en sus casos, pues los perpetradores se encuentran libres o no se han hecho las investigaciones de rigor. En su lucha por el reconocimiento, las tres defensoras de derechos humanos han obtenido más una resonancia en el ámbito de la solidaridad que en las esferas jurídicas. Los organismos nacionales y los organismos internacionales de defensa de derechos han tomado, al menos en dos de ellos, como casos emblemáticos.

\section{Discusión}

Si bien como afirma Nussbaum, teniendo como referente el mito griego de la venganza Clitemnestra, "el resentimiento desbocado, que es obsesivo, destructivo y cuya única razón de ser es infligir dolor y desgracia” (2019, p. 91), también podemos concebir esta emoción como benigna o al menos no destructora, y en algunos casos, una fuerza afectiva con poder moral o político que ayuda a la protesta y a la reivindicación de derechos. 
Una tradición ha concebido este sentimiento solo desde la perspectiva del pensador alemán Nietzsche, como una reacción de los débiles que es, ante todo, una "venganza imaginaria", que apunta a "transvaloración o inversión de los valores sustentados por los nobles” (Escribar, 2000, p. 57). Así concebido, el resentimiento se le despoja de su dimensión política, y se le constriñe a un ámbito muy restringido de la moral en términos negativos. Y si bien, tradicionalmente se le asocia con la envidia, incluso con el perdón, en tanto es el supuesto envés de éste, en las últimas décadas varios investigadores y pensadores lo han articulado con expresiones políticas como la emancipación, el populismo o la xenofobia. Un ejemplo de esto, es expuesto por De Swaan (2016) y Smith (2016), quienes afirman que la xenofobia, y posterior exterminio de judío, se debió a una rivalidad con esta comunidad que había logrado un éxito social y cultural, lo cual generó resentimiento, envidia y prácticas xenófoba apoyadas por un populismo nacionalista y racista al interior de la sociedad alemana.

Ya Améry había denunciado lo restringido de la concepción nietzscheana para pensar el resentimiento asociado con los débiles. Para este pensador que fue víctima de torturas por los nazis, la víctima, por el contrario, los 'débiles', pueden erigir su odio contra el verdugo como portaestandarte moral. El resentido posee una conciencia moral, que distingue muy bien la 'víctima' y el verdugo. A diferencia del postulado nietzscheano que afirma que las personas 'resentidas' padecen una envidia que idean sin llevar a cabo su 'venganza imaginaria', el resentimiento que se expresa en emociones como el odio, la rabia, la tristeza, etc., puede ser un motor para la acción, incluso para exigir justicia. En palabras de Arias (2015), la "Función del resentimiento será entonces dice Améry- proporcionar realidad moral al delito a ojos del criminal” (s/d). Más allá de la 'venganza imaginaria', la 'víctima' puede en su accionar político y reivindicación ética, luchar por denunciar el menoscabo de sus derechos y la reivindicación de justicia, aun cuando el crimen sea imperdonable.

Quizá en el contexto del pensamiento de Nietzsche, su lucha contra el 'cristianismo' acotó ingenuamente un concepto más rico en matices y posibilidades emancipatorias que las que propone del autor de la genealogía de la moral en Occidente. 
No solo Améry, sino que las denominadas víctimas en América Latina, han expresado su resentimiento abiertamente a los victimarios y han hecho de este odio un aliciente para su activismo político. Como lo expresa en una entrevista la defensora de derechos humanos Graciela Fernández Meijide, cuyo hijo fue desaparecido por la Junta Militar argentina: "yo aprendí a odiar al que le estaba causando sufrimiento a Pablo, a los que nos causaban un brutal sufrimiento a toda la familia" (La Nación, 2017). Y agregó: "Si alguna vez creí haber sabido lo que era el odio... ahí me lo enseñaron”. Ella recreaba en su 'venganza imaginaria', que le "pegaba un tiro a [militares golpistas] Videla, Massera y Agosti”. Esos fantaseos le permitieron 'canalizar el odio', hasta convertirse en una defensora de derechos humanos.

Los dos grupos de mujeres que participaron en esta investigación manifestaron malestar subjetivo que suele asociarse con el resentimiento (rencor, odio, deseos de venganza, etc.). El resentimiento es una emoción que está compuesta de múltiples manifestaciones negativas contra los que han hecho daño a otro, lo que suscita odio, desprecio, etc. En el caso comparativo abordado anteriormente, las mujeres expresan estos sentimientos en un lenguaje emocional, como "rabia contra los que mataron a mis hijos", "contra la sociedad" por su falta de solidaridad, o una desvalorización de la vida social o personal.

Aunque estas reacciones suelen ser pensadas dentro de un cuadro psicopatológico, lo que evidencia un enfoque psicosocial, más allá del trauma clínico, es una afectación individual con consecuencias en la sociedad, en la democracia y en el lazo social en general. Los conflictos armados, ya sean políticos o sociales, suelen afectar a grupos amplios de individuos, lo cual puede tener efectos negativos, no sólo para la convivencia entre cercanos, sino que suele destruir las organizaciones sociales que permiten la participación de los individuos en sus comunidades. Ese crimen, percibido por el individuo como una afectación personal, produce resonancias en otros ámbitos sociales

En uno y otro grupo, así se den respuestas cotidianas o discursos racionales de los derechos humanos, las denominadas emociones negativas afloran en los encuentros y en las entrevistas. Mientras en el primer grupo su manifestación es directa, en el segundo grupo está mediatizada por los referentes éticos y 
políticos del discurso de los derechos humanos. Mientras en el segundo grupo tiene como horizonte la justicia social y jurídica, el primero no hace una reivindicación de derechos, aunque también expresa la necesidad de justicia, y un más allá de la justicia (por ejemplo, la venganza).

Las mujeres de los talleres relatan los crímenes contra sus familiares y su padecimiento desde entonces, pero no reivindican una memoria para la justicia. Como lo afirmó una de ellas, al relatar lo que siente, se da una "descarga” emocional; así manifestarán en algún momento del taller la inutilidad de contar qué pasó, al final reivindicaban un espacio como ese, en el cual podían expresarse sin ser juzgadas o presionadas para contar sus historias que consideraban hasta entonces que debían permanecer en la esfera privada.

En el caso de estas las mujeres sin un trabajo de empoderamiento, la rabia, el odio y el deseo de venganza se condensan en un sentimiento de impotencia; así se permitan fantasías sádicas, pareciera que no logran dar una canalización expresiva a una manifestación más intersubjetiva, ya sea por la vía del trabajo comunitario, el arte, la lucha política o la búsqueda de justicia y memoria por lo padecido sus seres queridos.

El daño transformó las vidas y las identidades de estas mujeres, sometidas por efecto de la violencia a una memoria dolorosa que tiene consecuencias más allá de las esferas privadas. Tanto las mujeres del taller como las tres entrevistadas, sienten una gran desconfianza por el Estado y la justicia colombiana. Pero mientras las activistas de derechos humanos utilizan recursos legales (demanda de su caso ante cortes nacionales o internacionales), las otras mujeres recurren a un cuestionamiento de la ineficacia del Estado, en lo social, en la seguridad o la justicia, sin emprender una lucha para reivindicar el asesinato de sus hijos.

Todas las mujeres afirman que la solidaridad de los hijos o esposos, vecinos, amigos y familiares, les permitieron enfrentar con mayor valor las violencias contra sus hijos o las violencias padecidas. En el caso de las activistas de los derechos humanos, afirman, que además del apoyo de hijos o esposos cuando éste se daba, contaron con una red social de organizaciones que dieron dirección a sus reclamos y la vocación por la defensa del caso de sus familiares o de otras personas que compartían como víctimas estos hechos como la desaparición forzada o las ejecuciones extrajudiciales de alguno de su familia o varios. 
En el lenguaje moral, la mayoría de las mujeres del taller expresa el no perdón, o tienen dudas para otorgarlo. En el caso de las defensoras de derechos humanos, mientras alguna tiene como consigna de "no perdón ni olvido" (Fabiola Lalinde), otra afirma que es necesario el perdón (Pastora Mira), u otra considera que más allá del perdón está la justicia (Luz Marina Bernal).

A diferencia de un odio ideologizado o político, como se presenta en formas como el racismo, la homofobia o la exclusión del diferente, las mujeres del taller participaron en la investigación, presentan un odio difuso a los perpetradores o los grupos que lo representan, haciendo extensivo este odio, desprecio o desconfianza a cualquier grupo armado (ilegal o legal).

Aunque el resentimiento es una respuesta moral al daño, genera a su vez múltiples respuestas desde una desconfianza por las instituciones y la sociedad, hasta un activismo político por reivindicación de derechos. Como advierte Honneth (2010), para la filosofía política el objetivo normativo ya no es eliminar la desigualdad sino prevenir la humillación o el menosprecio.

En un país como el colombiano, la filosofía política debe orientarse tanto en el objetivo normativo de la distribución de la riqueza como la dignidad y el respeto por cada una de estas mujeres que han sobrevivido en medio de la marginalidad o el riesgo de sus vidas, como acontece con las defensoras de derechos humanos.

\section{Referencias}

Ahmed, S. (2015). La politica cultural de las emociones. México: Universidad Autónoma de México.

Améry, J. (2001). Más allá de la culpa y la expiación.Valencia: Pre-textos.

Arias, M. (2015). El resentimiento en la democracia. Revista de datos. Recuperado de https://www.revistadelibros.com/articulo_imprimible.php?art=931\&t=blogs

Buela, A. (2009). Notas. El resentimiento. Estudios, 90, 143-148.

Darwin, C. (1998). La expresión de las emociones en los animales y en el hombre. Madrid: Alianza editorial. 
Demertzis, N. (2013). Introduction: Theorizing the Emotions-Politics Nexus. En N. Demertzis. (Ed.), Emotions in Politics. The Affect Dimension in Political Tension (pp. 1-16). New York: Palgrave Macmillan.

De Swaan, Abram (2016). Dividir para matar. Bogotá: Semana Libros.

Díaz, J. (1994). El resentimiento como argumento moral. Ideas y Valores, 43(94), 11-20.

Escríbar, A. (2000). Nietzsche y el resentimiento. Revista de filosofía, 57-65.

Feldman, L. (2018). La vida secreta del cerebro. Bogotá: Paidós.

Fundación Solidaridad y Compromiso (s/f). Recuperado de https://www.fusolcom.org/

Fukuyama, F. (2019). Identidad. Bogotá: Editorial Planeta Colombiana S.A.

Harari, Y. (2016). Homo Deus. Bogotá: Debate.

Honneth, A. (2010). Reconocimiento y menosprecio. Sobre la fundamentación normativa de una teoría social. Madrid: Katz Editores.

Illouz, E. (2012). Por qué duele el amor. Buenos Aires: Katz Editores.

Jasper, J. (2013) Las emociones y los movimientos sociales: veinte ańos de teoría e investigación. Revista Latinoamericana de Estudios sobre Cuerpos, Emociones y Sociedad, 10(4), 46-66.

Judis, J. (2018). La explosión populista. Bogotá: Deusto.

Laing, O. (2017). La ciudad solitaria. Madrid: Capitán Swing.

Lefranc, S. (2017). La venganza de las víctimas. Revista de estudios sociales, 59, 140-144.

La Nación (28/09/2017). Graciela Fernández Meijide: “Aprendí a odiar con la desaparición de mi hijo". Recuperado de http:/www.lanacion.com.ar/2067190-graciela-fernandez-meijide-aprendi-a-odiar-con-la-desaparicion-de-mi-hijo

Maldonado, M. (2017). Las bases afectivas del populismo. Revista Internacional De Pensamiento Político, 12, 151-167.

Marrades, J. (2004). Resentimiento y verdad. Sobre la réplica de Améry a Nietzsche. ISEGOR, 131, 221-236.

Mishra, P. (2017). La edad de la ira. Barcelona: Galaxia Gutenberg.

Molina, L., Ramírez, L., Arroyave, E., Piedrahita, I., Orrego, C., López, M.; Marín, J., y Vallejo, A. (2016). Taller exploratorio en torno al perdón. Medellín: Universidad Antioquia. 
Nussbaum, M. (2014). Emociones políticas. Bogotá: Editorial Planeta Colombiana S.A.

Nussbaum, M. (2019). La monarquía del miedo. Bogotá: Editorial Planeta Colombiana S.A.

Rueda, C. (2012). Perdón y arrepentimiento: la experiencia de Jean Améry. Ideas y Valores, LXI (148), 79-99.

Smith, R. (2016). Schadenfreude. La dicha por el mal ajeno. Madrid: Alianza editorial.

Salas, Á, (2008). Resentimiento en el paramilitarismo. Análisis del discurso de Carlos. Bogotá. Editorial Universidad del Rosario.

Socarrás, J. (1994). Laureano Gómez. Psicoanálisis de un resentido. Bogotá: Planeta colombiana.

Traister, R. (2019). Buenas \& enfadadas. Madrid: Capitán Swing.

Reyes, V. (1944). El resentimiento, sus causas y consecuencias. Revista de la Universidad Católica, 179-189. 